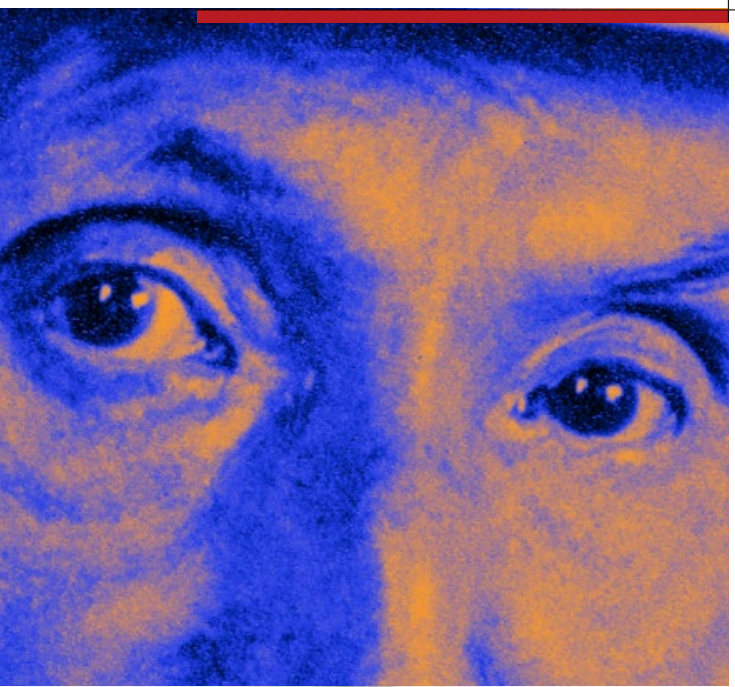

\title{
Erfinder der Ergotherapie
}

\section{Pierre-Auguste Renoir}

\author{
Man sieht seinen Bildern nicht an, ob er sie mit der rechten oder linken \\ oder mit einer extrem deformierten Hand bei nahezu vollständiger \\ Bewegungsunfähigkeit gemalt hat. Pierre-Auguste Renoir (1841-1919) \\ konnte sich berauschen an der Schönheit.
}

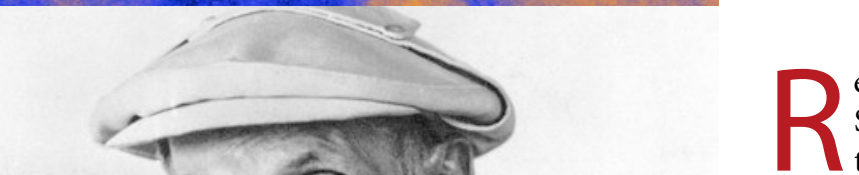

enoir liebte das Leben und das Schöne, trotz der Schmerzen. Erste Symptome der rheumatoiden Arthritis traten im Alter von etwa 50 Jahren auf. Auf einer Fotografie aus dem Jahre 1896 sind deutliche Schwellungen der Metakarpophalangealgelenke zu erkennen. Die Krankheit verlief mit schweren Schüben und fesselte ihn zuletzt an den Rollstuhl. Fast bewegungsunfähig, kachektisch und gequält von Schmerzen und Dekubitalulzera malte er dennoch großformatige Bilder, indem er verschiedene Hilfsmittel benutzte.

Vorm Malen wurde erstmal jongliert: Nach einem schweren Anfall im Dezember 1897 fing Renoir an, körperliche Übungen zu betreiben, vor allem um seine Hände beweglich zu halten. So jonglierte er jeden Morgen, bevor er sich ins Atelier begab, mit Lederbällen, als das später nicht mehr ging, mit einem Holzstab. Dabei sei es ihm nicht darum gegangen, gesund zu werden, schrieb Renoirs Sohn Jean in seinen Erinnerungen. Ihm ging es ausschließlich ums Malen. Der Rheumatologe Prof. Dr. H. Zeidler, Hannover, hat Renoir deshalb auch als „Erfinder der Ergotherapie“ bezeichnet.

Konnte Renoir 1901, als sein jüngster Sohn geboren wird, seine Hände noch normal benutzen, sind sie zwei Jahre später bereits erheblich deformiert. Zum Laufen benötigt er einen Stock, ab 1912 den Rollstuhl. Sein etwa ab 1902 zunehmend starrer Gesichtsausdruck geht offenbar auf eine teilweise linksseitige Gesichtslähmung zurück, die man mit Elektrotherapie zu behandeln versuchte. Renoir hatte zudem stark an Gewicht verloren. In einem Brief schrieb er: „46 Kilo, das kann man nicht fett nennen.“
Doch ungeachtet aller Probleme blieb er mindestens so produktiv wie zuvor.

Mehrfach reist er wegen des warmen Klimas mit Familie und Personal nach Südfrankreich. Später kauft er sich ein Anwesen in Cagnes-sur-Mer, nahe Nizza. Doch selbst im mediterranen Klima ist er stets warm gekleidet. Gerne darf eine der vielen Katzen, die auf dem Grundstück leben, ihre Körperwärme mit Renoir teilen - ein Grund, warum auf manchen Renoir-Bildern Katzenhaare gefunden wurden. Das Malen war Renoir nicht nur ein physisches Bedürfnis, es war auch Therapie. Wenn er nachts die Schmerzen nicht aushalten konnte, ließ er sich ein Holztäfelchen, Pinsel und Farbe bringen, etwa um ein paar Blumen zu malen.

Pinsel steckten ihm andere an: Die fortschreitenden Handdeformitäten und die Ankylose der rechten Schulter zwangen Renoir, seine Maltechnik kontinuierlich anzupassen. Die Pinsel steckten ihm seine Frau, sein Sohn oder das jeweilige Modell in die Hände. Die auf Fotos sichtbaren Bandagen dienten dazu, Schweiß aufzunehmen und die empfindliche Haut zu schützen. Später erfand er eine drehbare Zylinderstaffelei, die ihm noch $1918 / 19$ erlaubte, das $160 \times 110 \mathrm{~cm}$ große Gemälde „Die Badenden“ fertigzustellen.

Am 3. Dezember 1919 malte Renoir Anemonen, die das Hausmädchen für ihn gepflückt hatte. Sein Sohn schreibt: "Mehrere Stunden lang identifizierte er sich mit diesen Blumen und vergaß sein Leiden darüber. Dann gab er ein Zeichen, man möge ihm den Pinsel wieder abnehmen, und sagte: ,Ich glaube, allmählich verstehe ich etwas davon.' ... Er starb in der gleichen Nacht.“

(TM) 